\title{
A Musicoterapia e o Transtorno do Espectro do Autismo: uma abordagem informada pelas neurociências para a prática clínica
}

\author{
Music therapy and Autism Spectrum Disorder: \\ a neuroscience informed rationale for clinical practice
}

\section{Renato Tocantins Sampaio ${ }^{1}$ \\ Cybelle Maria Veiga Loureiro ${ }^{2}$ \\ Cristiano Mauro Assis Gomes ${ }^{3}$}

\footnotetext{
${ }^{1}$ Universidade Federal de Minas Gerais, Belo Horizonte, Minas Gerais, Brasil. renatots@musica.ufmg.br

2 Universidade Federal de Minas Gerais, Belo Horizonte, Minas Gerais, Brasil. cybelleveigaloureiro@gmail.com

3 Universidade Federal de Minas Gerais, Belo Horizonte, Minas Gerais, Brasil. cristianomaurogomes@gmail.com
}

\section{Resumo:}

Nos últimos anos, muitos estudos em neurociências têm buscado compreender como o sistema nervoso está estruturado, como funciona em pessoas com desenvolvimento global típico e atípico, e como este sistema nervoso processa a música enquanto estímulo percebido e ação no mundo. A integração destes conhecimentos na prática clínica musicoterapêutica pode fornecer novas explicações sobre o modo pelo qual o uso terapêutico da música promove melhoras da saúde, bem como subsidiar o desenvolvimento de novas abordagens clínicas de tratamento, avaliação diagnóstica e avaliação do processo terapêutico. Este artigo apresenta uma fundamentação nas neurociências para uma prática clínica musicoterapêutica com foco na melhora da comunicação não-verbal e da interação social de crianças e adolescentes com Transtorno do Espectro do Autismo. 
Palavras-chave: Fundamentação Clínica Musicoterapêutica; Transtorno do Espectro do Autismo; Neurociências; Interação Musical; Comunicação Musical.

\begin{abstract}
:
In the last years, many studies in neurosciences aimed at understanding how the nervous system is structured, how it works in people with typical and atypical global development, and how music is processed as perceived stimulus and action in the word. The integration of this knowledge in music therapy clinical practice may provide new explanations about the path in which the therapeutic use of music improves health as well as assist the development of new clinical approaches for treatment, assessment and evaluation. This article presents a neuroscience rationale of a music therapy clinical practice with focus on nonverbal communication and social interaction for children and teenagers with Autism Spectrum Disorder.
\end{abstract}

Keywords: Music Therapy Clinical Rationale; Autism Spectrum Disorder; Neurosciences; Musical Interaction; Musical Communication.

Data de recebimento: 03/05/2015

Data de aprovação final: 05/09/2015

\title{
1 - O Transtorno do Espectro do Autismo
}

O Transtorno do Espectro do Autismo (TEA) é uma desordem do neurodesenvolvimento com início precoce e curso crônico, não degenerativo. O processo de diagnóstico é fundamentalmente clínico e abarca prejuízos na interação social, alterações importantes na comunicação verbal e não-verbal e padrões limitados ou estereotipados de comportamentos e interesses, dentre outros sinais e sintomas (APA, 2014). A etiologia do Transtorno do Espectro do Autismo ainda é desconhecida, embora muitos estudos em genética e neuropsicologia referendem a compreensão deste quadro como biologicamente determinado (ASSUMPÇÃO et al., 1999; CARVALHEIRA; VERGANIB; BRUNONI, 2004; GUPTA; 
STATE, 2006; MECCA et al., 2011; PEREIRA; RIESGO; WAGNER, 2008; VELLOSO et al., 2011).

Além das alterações na tríade autística clássica (interação, comunicação e comportamento), verifica-se a presença de déficit intelectual em, pelo menos, 60 a 70\% da população com autismo infantil típico, embora estudos realizados nas últimas décadas tenham sugerido que uma estimativa menor desta comorbidade ${ }^{1}$ possa ser encontrada a partir de modos mais sensíveis de avaliação de funções comunicativas e funções executivas (GIRODO, NEVES, CORREA, 2008; KLIN, 2006; TAMANAHA; PERISSINOTO; CHIARI, 2008). Há também relatos de prejuízos no desenvolvimento motor (BHAT; LANDA; GALLOWAY, 2011; MATSON; MATSON; BEIGHLEY, 2011), nas funções executivas (CAMARGO, BOSA, 2012; DICHTER; FELDER; BODFISH, 2009; DICHTER, 2012; ORSATI et al., 2008; TOWGOOD et al., 2009) e em componentes específicos de processos comunicativos (CAMPELO et al., 2009; FERREIRA; TEIXEIRA; BRITTO, 2011; KLIN, 2006; VELLOSO et al., 2011). Estima-se comorbidade com transtorno mental em cerca de $71 \%$ das pessoas com TEA, sendo que cerca de $41 \%$ das pessoas com TEA apresentariam dois ou mais transtornos associados, com destaque para transtorno depressivo, transtorno de ansiedade, transtorno obsessivo compulsivo, fobias e transtorno de déficit de atenção com hiperatividade, dentre outros (WORLEY, MATSON, 2011).

Devido à grande variabilidade de fenótipos clínicos e de alterações biológicas, muitos clínicos e pesquisadores questionam a possibilidade de uma etiologia única para todo o continuum do espectro autístico (SCHARTZMAN, 2011), bem como uma abordagem totalmente unificada tanto para as pesquisas como para as intervenções de reabilitação baseadas em evidências (ASSUMPÇÃO et al., 1999; BOSA, 2001; CAMARGO; BOSA, 2012, TOWGOOD et al., 2009).

Vários estudos descrevem ou propõem a existência de alterações diversas no sistema nervoso central que poderiam explicar o autismo ou, pelo menos, parte das alterações significativas

1 Comorbidade significa a presença de dois ou mais quadros patológicos concomitantes. Por exemplo, no Transtorno do Espectro do Autismo, os sinais autísticos podem vir acompanhados (em comorbidade) ou não (sem comorbidade) com a deficiência intelectual, o atraso no desenvolvimento motor, o transtorno de déficit de atenção com hiperatividade etc. 
nas interações sociais, comportamento e comunicação, dentre outros achados clínicos. Por exemplo, Damásio e Maurer, citados por SCHARTZMAN (2011), a partir da comparação de comportamentos encontrados em pessoas com TEA e em adultos com lesões corticais adquiridas, sugeriram que haveriam alterações anatômicas e/ou fisiológicas em várias regiões do sistema nervsoso, tais como giro do cíngulo, área entorrinal, área perrinial, giro para-hipocampal, regiões subicular e pré-subicular, dentre outras. ${ }^{2}$

Já SCHARTZMAN (2011), verificando problemas na Teoria da Mente $^{3}$ em pessoas com TEA, supõe alterações no córtex-orbito-frontal, lobos temporais e corpo amigdalóide.

AMARAL, SCHUMANN e NORDAHL (2008, p.138) relacionaram áreas do sistema nervoso, as quais pesquisas com animais, com pacientes com lesões corticais e com neuroimagem de pessoas com desenvolvimento típico já estabeleceram associações com os marcadores clínicos alterados em pessoas com TEA. Segundo estes autores, estão relacionados aos prejuízos sociais no autismo o córtex órbito-frontal, o córtex cíngulo anterior, o giro fusiforme, o sulco temporal superior, a amígdala, o giro frontal inferior e o córtex parietal posterior. Para os déficits de comunicação, estão listados o giro frontal inferior, o sulco temporal superior, a área motora suplementar, os gânglios da base, a substância negra, o tálamo e os núcleos cerebelares da ponte. Em relação aos comportamentos repetitivos e estreotipados, os autores elencam o córtex órbito-frontal, o córtex cíngulo anterior, os gânglios da base e o tálamo. É importante ressaltar que uma mesma região cerebral pode estar relacionada a mais de uma alteração funcional; por exemplo, o córtex órbito-frontal está associado tanto com os prejuízos na interação social como na presença de comportamentos repetitivos.

2 Devido ao escopo e tamanho deste artigo, não é possível uma descrição de todas as áreas do sistema nervoso e suas supostas funções possivelmente alteradas no Transtorno do Espectro do Autismo. Para uma compreensão geral da anatomia e funcionamento do Sistema Nervoso Humano, sugerimos a leitura dos livros "Cem bilhões de Neurônios?", de ROBERTO LENT (2010), e "Fundamentos de Neuroanatomia", de RAMON M. COSENZA (1998).

3 Segundo BOSA e CALLIAS (2000), Teoria da Mente corresponde à capacidade de uma pessoa para fazer inferências sobre os estados mentais de outras pessoas e, a partir de tais representações, compreender com estas pessoas se sentem e predizer o comportamento delas. Essa capacidade teria um impulso inicial inato, porém o processo em si seria aprendido por meio das interações com os cuidadores e com outras pessoas, o que implicaria em diferenças culturais no resultado do desenvolvimento deste processo. BOSA e CALLIAS explicam que o termo 'teoria' é utilizado pois o processo envolve um sistema de inferências sobre estados que não são diretamente observáveis e que podem ser usados para explicar e predizer o comportamento. 
NEUHAUS, BEAUCHAINE e BERNIER (2010) listam como regiões que comporiam o chamado "cérebro social" o sulco temporal superior, o giro fusiforme, a amígdala e córtex pré-frontal, além de áreas relacionadas ao sistema de neurônios espelho, mais especificamente áreas do córtex frontal inferior e do lóbulo parietal inferior. Para estes autores, no TEA, há evidências empíricas de alterações na amígdala, no sistema dopaminérgico mesolímbico e no sistema de oxitocina que poderiam explicar déficits sociais nesta população ${ }^{4}$.

NEUHAUS, BEAUCHAINE e BERNIER (2010) referem, ainda, falhas na conectividade entre diversas regiões cerebrais em pessoas com TEA, tais como reduções em conectividade de longo alcance entre áreas do córtex frontal e parietal, que favoreceriam a diminuição da integração sensorial, o que traria prejuízos para o processamento dos estímulos sociais, e conectividade local, que aumentariam a possibilidade de regiões hiperespecializadas promoverem estratégias de processamento orientadas para detalhes ao invés de para a configuração geral. Pessoas com TEA também foram descritas como apresentando redução significativa no volume do corpo caloso, como um todo e em várias de suas partes, além de alterações anatômicas (forma) da região medial e redução da integridade da matéria branca.

Como resultante dos estudos acima mencionados, verifica-se, então, que há uma grande variedade de áreas candidatas a estarem alteradas em pessoas com TEA, além de eventuais problemas de conexão entre elas, porém não há homogeneidade entre estas várias proposições. Ainda, nestes poucos exemplos, dentre os muitos artigos encontrados na literatura recente, foram abordadas prioritariamente essas anomalias em áreas cerebrais específicas e mencionadas algumas pequenas alterações nas conexões entre regiões cerebrais, mas não foram abordados outros aspectos do funcionamento do sistema nervoso como as interações com o sistema endócrino e o imunológico devido ao escopo deste estudo.

\footnotetext{
4 Segundo BARTELS e ZEKI (2004), estudos comportamentais, celulares e neuroendócrinos com várias espécies de mamíferos, de roedores a primatas, tem demonstrado o envolvimento de neurohormônios como a oxitocina e vasopressina na formação e manutenção de um forte envolvimento afetivo interindividual e, também, um acoplamento entre os processos de apego e os sistemas neurais de recompensa. Em humanos, estudos relatam que estes neurohormônios estão também envolvidos na vinculação entre mãe e filho (em ambas as direções) e em relações afetivas de longa-duração entre adultos. No entanto, MERCADANTE e POLIMENO (2009) alertam que vários estudos com pessoas com TEA têm utilizado uma dosagem de vasopressina e oxitocina no sangue, o que não necessariamente corresponde à dosagem destas substâncias no cérebro e que, portanto, mais estudos são necessários para um maior conhecimento do papel da oxitocina e da vasopressina no funcionamento cerebral de pessoas com TEA.
} 
É importante ressaltar, no entanto, que existem estudos sobre anormalidades em áreas cerebrais e das alterações de conexão entre elas, como o trabalho de DICHTER, FELDER e BODFISH (2009), que realizaram uma revisão de literatura sobre os achados referentes a ressonância magnética funcional em pessoas com TEA. Tal revisão, apesar das diferenças metodológicas dos estudos, encontrou: 1) hipoativação em áreas do "cérebro social" durante o processamento de tarefas sociais; 2) ativação irregular frontoestriatal durante tarefas relevantes para comportamentos repetitivos e comportamentos restritivos; 3) lateralização diferenciada durante tarefas de processamento de linguagem verbal; 4) respostas mesolímbicas atípicas em situações de recompensa social e não-social; 5) hipoconectividade e hiperconectividade durante tarefas de longa duração; e 6) diminuição de conectividade anterior-posterior durante momentos de descanso.

Contudo, SCHWARTZMAN (2011) refere, com bastante pertinência que, embora tenham sido observadas anormalidades neurobiológicas em boa parte das pessoas com TEA, tal fato não significa que se tenha encontrado a causa do autismo. Assim como talvez uma única alteração genética não possa ser responsabilizada por todo o Transtorno do Espectro do Autismo, provavelmente haverá muitos marcadores biológicos distintos, o que atualmente impede a determinação de um único marcador que possa ser considerado específico ou patognomônico.

\footnotetext{
Inúmeros trabalhos clínicos, experimentais e baseados em exames de imagem realizados nas últimas décadas têm demonstrado a relação dos TEA com várias alterações biológicas e, mais recentemente, o interesse dos estudiosos tem se voltado para a identificação de quais são essas alterações e de como podemos relacionar os achados anatômicos e fisiológicos com o quadro clínico destas condições.

A ideia de que os vários TEA teriam a mesma alteração neurobiológica de base parece não ser mais provável, mas talvez devêssemos admitir que os quadros clínicos dos TEA poderiam ser decorrentes de alterações diversas, comprometendo estruturas variadas que, uma vez alteradas, resultariam em comportamentos similares (SCHWARTZMAN, 2011, p.66).
}

\section{1 - A Cognição Social no TEA}

A Cognição Social pode ser compreendida como o conjunto de processos cognitivos ativados em situações de interação social. Estes processos permitem perceber, avaliar e responder às situações de interação social, não somente avaliando as próprias impressões, 
como também inferindo opiniões, crenças ou intenções dos outros, e então, responder a essas situações. A cognição social pode ser subdividida em diferentes subprocessos: 1) Percepção Social: inclui a capacidade de avaliar regras e papéis sociais, assim como para avaliar o próprio contexto social; 2) Conhecimento Social ou conhecimento dos aspectos particulares de cada situação social; 3) Estilo Social: forma com que cada pessoa interpreta e explica as causas de um resultado determinado, negativo ou positivo; 4) Teoria da Mente: capacidade para fazer inferências sobre os estados mentais de outras pessoas e, a partir de tais representações, predizer o comportamento destas pessoas; 5) Processamento Emocional: capacidade para compreender, expressar e manejar as emoções; e 6) Empatia: processo de se pôr no lugar do outro a fim de sentir como ele se sente. A empatia pode ser considerada como um componente transversal que influencia tanto o funcionamento da Teoria da Mente como o Processamento Emocional (GARCIA; USTARROZ; LOPEZ-GOÑI, 2012).

ARAUJO (2000), BOSA e CALLIAS (2000) e GIRODO, NEVES e CORREA (2008) informam que vários estudos acerca da Teoria da Mente afirmam que as pessoas com TEA demonstram incapacidade ou falhas em realizar metarrepresentações, que são representações sobre os estados mentais de outras pessoas. Tais falhas na metarrepresentação dificultam ou impedem as pessoas com TEA de compreender o que as outras pessoas estariam pensando, o que poderia explicar os graves prejuízos na interação pessoal, principalmente naquelas pessoas no polo menos funcional do espectro.

Segundo BOSA (2009), o recém-nascido com desenvolvimento típico progride da habilidade de olhar predominantemente para o adulto, para se interessar pelo mesmo foco do olhar dos adultos, e depois considerar adultos como pontos de referência social, e então, agir sobre objetos da forma como o adulto reage, finalmente, dirigindo a atenção do adulto para si e para os eventos, tanto para buscar assistência quanto para compartilhar o mesmo foco de atenção. Essas habilidades constituem a base da aquisição da comunicação linguística e da teoria da mente. "A criança cedo descobre que um foco comum de atenção pode ser seguido, direcionado e, finalmente compartilhado por meio de vários canais comunicativos" (BOSA, 2009, p.320). 
NEUHAUS, BEAUCHAINE e BERNIER (2010) descrevem cinco áreas de funcionamento social afetadas em pessoas com autismo que podem ser observadas em crianças até 6 anos. A primeira área consiste na tendência para direcionar a atenção espontaneamente para o estímulo social, comportamento este que pode ser encontrado em crianças recém-nascidas, como mencionado anteriormente, mas está ausente ou diminuído em muitas pessoas com TEA. Uma segunda área, talvez decorrência da anterior, é a atenção compartilhada (joint attention), isto é, a habilidade para compartilhar, seguir ou direcionar a atenção em conjunto com outras pessoas que, tipicamente, já está presente em crianças ao longo do primeiro ano de vida e dá suporte para o desenvolvimento linguístico e o desenvolvimento de habilidades sociais subsequentes. Crianças com TEA demonstram déficits em iniciar e em seguir a atenção compartilhada ${ }^{5}$.

A terceira área prejudicada é o processamento de informações faciais. Desde os primeiros momentos após o nascimento, a criança com desenvolvimento típico direciona o olhar e a atenção em geral para faces humanas. Pessoas com autismo, além de em muitas ocasiões evitar o contato visual com outras pessoas, são descritas como tendo um processamento de informações a partir da face menos holístico que pessoas com desenvolvimento típico, dando ênfase exagerada a partes da face em detrimento de uma percepção mais geral, por exemplo, focando somente ou prioritariamente a boca e não notando durante a interlocução os movimentos oculares, de sobrancelha, de testa etc., o que, por sua vez, ocasionaria perda de importantes dicas não-verbais nos processos comunicativos ${ }^{6}$.

A imitação motora consiste na quarta área onde há diferenças, pois, enquanto as crianças com desenvolvimento típico já iniciam imitações motoras em algumas poucas semanas após seu nascimento, crianças com TEA apresentam déficits na imitação espontânea e imediata de movimentos básicos de mãos, rosto e outras partes do corpo, assim como no manuseio

\footnotetext{
5 A atenção compartilhada foi ainda descrita como "comportamentos infantis os quais revestem-se de propósito declarativo, na medida em que envolvem vocalizações, gestos e contato ocular para dividir a experiência em relação às propriedades dos objetos/eventos a seu redor" (BOSA, 2002, p.81). Bruner, citado por BOSA (2002) argumentou que o bebê, ao tomar parte em uma mesma atividade repetidamente, passa a entender as demandas e as formas apropriadas de comunicação que são culturalmente determinadas e requeridas para aquela atividade. A natureza ritualística, isto é a constância, a frequência e a repetição dessas atividades, é importante para que os bebês desenvolvam uma comunicação intencional. No entanto, observa-se que crianças com autismo não ultrapassam este momento do ritual e permanecem com os comportamentos repetitivos e, muitas vezes, estereotipados.
}

6 Para maiores informações sobre as alterações no contato visual de pessoas com TEA recomenda-se a leitura de ORSATI et al. (2008) e KENET et al. (2012). 
simples de objetos. NEUHAUS, BEAUCHAINE e BERNIER (2010) referem também dificuldades das pessoas com TEA em discernir entre movimentos voluntários e involuntários dos outros, o que provavelmente estaria associado a déficits na Teoria da Mente. A última destas cinco dimensões envolve o nível de respostas a dicas emocionais de outras pessoas. Pessoas com TEA apresentam dificuldades de reconhecer emoções baseadas em dicas vocais e visuais e reagem com desinteresse ou repúdio às emoções expressas por meio de comportamentos diversos de outras pessoas.

\section{2 - Música e Musicoterapia no TEA}

A música é um fenômeno humano que está presente em todas as culturas conhecidas e tem sido utilizada desde entretenimento e o favorecimento de experiências estéticas a acalmar crianças agitadas, eliciar emoções, favorecer a coesão social, expressar consciência social e crenças religiosas, dentre várias outras funções (GFELLER, 2008; KOELSCH, 2014).

Estudos em neurociências têm demonstrado que há substratos biológicos inatos no ser humano que, ao mesmo tempo, possibilitam e constrangem o modo como a música ocorre. Os bebês humanos apresentam diversas habilidades musicais desde as primeiras semanas de vida, incluindo uma refinada percepção de alturas e padrões rítmicos, localização da fonte sonora, preferência por consonância à dissonância, correspondência entre som e movimento, dentre outros (TREHUB, 2005; ILARI, 2006).Vale ressaltar que apesar de aparentemente haver um substrato neural inato para alguns processamentos de informações musicais, a própria prática musical modifica o cérebro em termos anatômicos e fisiológicos (TREHUB, 2005; PASCUAL-LEONE, 2009) $)^{7}$.

70 Neurocientista Aniruddh Patel considera que a música não é um mero produto biológico adaptativo do homem ao mundo, como apenas uma resultante do processo de seleção natural, mas sim uma "tecnologia transformativa", isto é, um produto cultural com substratos biológicos que modifica o modo como interagimos com mundo e que traz vantagens aos seus portadores. No caso da música, tais vantagens seriam a facilitação da coesão social, do sentido de identidade social, bem como a vivência e a expressão emocional de um modo diferenciado das vivências emocionais do dia-a-dia, dentre várias outras. Para PATEL, assim como a linguagem escrita, a música é uma invenção cultural que possui um impacto profundo no modo como o ser humano vivencia o mundo como, por exemplo, poder conectá-lo a outros indivíduos de lugares e em tempos diferentes. Ressalta-se, contudo, que a música é um fenômeno universal enquanto que o letramento não apresenta a mesma distribuição. Ainda, a música como fenômeno cultural parece preceder a escrita em pelo menos 30 mil anos (PATEL, 2008a, 2008b). 
Ainda hoje, no entanto, não há consenso na literatura científica se há uma trajetória de desenvolvimento musical comum aos seres humanos, isto é, se este desenvolvimento percorre etapas escalonadas ou se dá de modo contínuo, nem se existem marcadores temporais específicos de desenvolvimento como ocorre em outras áreas como a motora ou da linguagem. Por exemplo, KENNEY (2008) considera que entre oito e dezoito meses o bebê realiza as primeiras tentativas de sincronizar o movimento a estímulos musicais ouvidos porém tal habilidade será dominada por volta de três anos. Até os cinco anos de idade, a criança já teria desenvolvidas as habilidades de palmear e andar sincronizando com o tempo da música. Já para GFELLER (2008), por volta de dois ou três anos de idade a criança já seria capaz de sincronizar ritmicamente e manter a pulsação por curtos períodos de tempo. Porém, somente por volta dos quatro anos de idade esta habilidade já estaria estabilizada em função do desenvolvimento motor amplo e fino.

A literatura sobre Autismo relata uma intensa relação das pessoas com tal transtorno e a música, sendo considerado o aspecto não-verbal da música o principal meio de engajamento entre a pessoa com TEA e seu interlocutor, seja quando apresentada uma música puramente instrumental, ou em situações de um texto cantado ou narrado (ALVIN, 1978; BALL, 2004; BROWN, 1994; BROWNELL, 2002; BUDAY, 1995; EDGERTON, 1994; MALLOCH; TREVARTHEN, 2009; OLDFIELD, 2001; ROBARTS, 1996).

Nas últimas décadas, muitos estudos em neurociências têm demonstrado que tanto a música instrumental quanto as canções consistem em excelentes elementos para estudo das emoções, uma vez que não somente são capazes de eliciar respostas com valência positiva e negativa, mas, também e principalmente, por estas respostas serem consistentes mesmo em indivíduos de culturas diferentes. Ativações foram registradas na amígdala, no hipocampo, no giro hipocampal, na ínsula, no lobo temporal e no estriato ventral, dentre outras regiões cerebrais (BRATTICO et al. 2011; FRITZ et al., 2009; GOSSELIN et al., 2007; GOSSELIN et al., 2011; KOELSCH et al., 2006; KOELSCH, 2011; MITTERSCHIFFTHALER et al., 2007; OMAR et al., 2011, SAMSON; EHRLE; BAULAC, 2001; WONG et al., 2012). Indivíduos com TEA, aparentemente, possuem uma ativação menor na área pré-motora e na ínsula anterior esquerda, em relação a sujeitos com desenvolvimento típico, em especial durante o 
processamento de música "alegre", neste caso definida como música tonal em andamento rápido e tonalidade maior (CARIA; VENUTI; FALCO, 2011).

A música não somente pode eliciar emoções mas também mobilizar processos cognitivos complexos como atenção dividida e sustentada, memória, controle de impulso, planejamento, execução e controle de ações motoras, entre outros. Em várias destas funções, um bom desempenho pode ser alcançado por meio da prática nas atividades musicais sociais cotidianas, enquanto um desempenho diferenciado na execução de instrumentos e outras práticas musicais avançadas necessitam de treinamento específico prolongado. Apesar de muitos estudos utilizarem apenas a audição musical para compreensão do processamento emocional de estímulos musicais, são nas experiências musicais ativas - ou seja, quando a pessoa toca um instrumento musical, canta, compõe, e improvisa - que se observam mais facilmente a presença destes processos cognitivos complexos e o desenvolvimento de habilidades relacionadas a eles (KOELSCH, 2011; RODRIGUES, 2012).

FILIPIC e BIGAND (2004) sugerem a existência de dois níveis de processamento emocional da música: um, mais imediato e direto, que ocorre em frações de segundo e, outro, mais longo, de aproximadamente um segundo ou mais, que envolve processamento cognitivo mais elaborado. ALLEN, DAVIS e HILL (2012) verificaram que adultos com TEA de alto desempenho apresentam respostas fisiológicas à música semelhante a adultos do grupo controle, o que sugere uma percepção básica emocional preservada, porém, possuem dificuldade em articular estas emoções de forma verbal. CARIA, VENUTI e FALCO (2011) encontraram resultados semelhantes com adolescentes com TEA. Com base nestes estudos, pode-se supor que as pessoas com TEA apresentam o nível mais básico e direto de processamento emocional musical preservado, enquanto processos cognitivos mais elaborados, que envolvem, dentre outros, a verbalização, capacidade de empatia e capacidade de antecipação, como evidenciado na Teoria da Mente, sofrem alterações que configuram justamente os sinais observáveis do TEA nas relações interpessoais.

LAI et al. (2012) verificaram que circuitos neurais usualmente associados com processamento de fala e de canções - em especial o giro frontal esquerdo inferior, o giro frontal superior e uma maior conectividade das regiões frontal e posterior - são preservados 
em pessoas com TEA embora sejam mais ativados na escuta de canções que na fala, quando comparados com um grupo controle de paridade de idade. Tais achados sugerem que os sistemas funcionais que processam a fala e as canções são mais efetivamente engajados para a canção que para a fala em pessoas com TEA, mesmo que as projeções das áreas corticais relacionadas a estas funções não possuam diferença significativa quando comparadas a controles com desenvolvimento típico. Tal fato pode explicar o sucesso de alguns tratamentos musicoterapêuticos que se baseiam na transmissão de informações por meio de texto cantado, como os referidos por KERN, WOLERY e ALDRIDGE (2007).

BERGER (2002) sugere que a presença de uma pulsação regular e previsível é o componente musical principal para explicar o prazer que a pessoa com TEA sente com a música, criandose assim um estímulo ambiental não ameaçador ou aversivo. No entanto, simultaneamente e relacionados ao pulso musical, vários outros elementos musicais são apresentados na música favorecendo a flexibilidade e a variação (HURON, 2006; SAMPAIO, 2006). Deste modo, o pulso e outros elementos musicais regulares e previsíveis favoreceriam uma experiência não ameaçadora ou aversiva à pessoa com TEA enquanto outros elementos musicais, como o contorno melódico e variações de timbre e de articulação, possibilitariam ir além dos comportamentos previsíveis e, até mesmo, inflexíveis e estereotipados. Vários outros autores da literatura musicoterapêutica corroboram esta teoria tanto no TEA como em outras populações clínicas (ALVIN, 1978; NORDOFF; ROBBINS, 2007; SAMPAIO, 2002, 2006; SUMMER, 2009; THAUT, 2008).

Segundo a Federação Mundial de Musicoterapia,

Musicoterapia é o uso profissional da música e de seus elementos como
uma intervenção em ambientes médicos, educacionais e cotidianos com
indivíduos, grupos, famílias ou comunidades que busca otimizar sua
qualidade de vida e melhorar sua saúde e bem-estar físico, social,
comunicacional, emocional, intelectual e espiritual. A pesquisa, a prática
profissional, o ensino e o treinamento clínico em musicoterapia são
baseados em padrões profissionais de acordo com contextos culturais,
sociais e políticos. (WORLD FEDERATION OF MUSIC THERAPY,
2011, tradução nossa)

A Musicoterapia consiste em um processo sistemático de intervenção no qual o terapeuta ajuda o paciente a promover sua saúde utilizando experiências musicais e a relação terapêutica (BRUSCIA, 2000). Na Musicoterapia, o paciente vivencia a música de forma 
ativa através de atividades de audição, performance, composição e improvisação musicais sendo que a seleção destas atividades é determinada pela necessidade clínica do paciente bem como por suas habilidades desenvolvidas e potenciais, gostos, histórico e ideias sobre a música, conjugados com a abordagem teórica e metodologia clínica adotadas pelo terapeuta (SAMPAIO; SAMPAIO, 2005).

O atendimento musicoterapêutico a pessoas com TEA é uma das áreas de prática clínica bem organizada e presente no Brasil e em vários países como Argentina, Estados Unidos, Inglaterra, entre outros (ADAMEK; THAUT; FURMAN, 2008; ANDRADE; PIMENTA, sine data; BARCELLOS, 2004; BENENZON, 1985, 1987; BOXILL, 1985; BRANDALISE, 1998, 2001; CRAVEIRO DE SÁ, 2003; MARANTO, 1993; WIGRAM; PEDERSEN; BONDE, 2002).

CRAVEIRO DE SÁ (2003) indica como principais objetivos clínicos musicoterapêuticos possíveis com a pessoa com Transtorno do Espectro do Autismo: entrar em comunicação, partindo do nível em que a pessoa se encontra; desenvolver e/ou ampliar a capacidade de autoexpressão; diminuir ou extinguir comportamentos patológicos indesejáveis, tais como isolamento, hiperatividade, autoagressividade, estereotipias, tensões emocionais, desorganizações da linguagem etc.; romper barreiras impostas pelos comportamentos obsessivos, ajudando a pessoa com autismo a assimilar mudanças e variações; ultrapassar ou remover obstáculos emocionais e/ou cognitivos existentes; desenvolver um senso de fluxo temporal; desenvolver e ampliar a comunicação através de uma linguagem não-verbal que requer compreensão, codificação e decodificação de símbolos convencionalizados; e, desenvolver a comunicação e a interação social, dentre outros.

Estudos recentes têm comprovado a eficácia do processo clínico musicoterapêutico e do uso da música com pessoas com autismo, principalmente em relação aos aspectos de comunicação e interação social (BHATARA et al., 2009; GATTINO et al., 2011; GOLD; WIGRAM; ELEFANT, 2006; KERN; ALDRIDGE, 2006; KERN; WOLERY; ALDRIDGE, 2007; KIM; WIGRAM; GOLD, 2009). 
WIGRAM e GOLD (2006) relatam que o processo clínico musicoterapêutico favorece a motivação, as habilidades de comunicação e de interação social, além de sustentar e desenvolver a atenção. Segundo estes autores, a previsibilidade da estrutura musical auxilia a interação recíproca, a tolerância e a flexibilidade fazendo emergir o engajamento social para construção da relação, promovendo um relacionamento interpessoal apropriado e significativo. Discutem, ainda, a aplicabilidade da Musicoterapia tanto para o atendimento propriamente dito como para uma abordagem diagnóstica complementar na qual habilidades relacionadas a escutar e fazer música, quase que unanimente mencionadas em relatos sobre condutas e interesses de pessoas com autismo, podem favorecer uma compreensão diferenciada de habilidades e limitações destas pessoas, bem como indicar formas de apoio importantes para aprendizagem e tratamento.

FREIRE (2014) avaliou o efeito do atendimento musicoterapêutico baseado na interação musical entre crianças com TEA e terapeuta durante a experiência musical de improvisação e verificou que, em média, com apenas quatro meses de sessões individuais semanais, utilizando o parâmetro estatístico $d$ de Cohen, já era possível verificar efeitos significativos de tamanho médio e grande em relação ao desenvolvimento da comunicação e da interação social. Os resultados deste estudo também sugerem, embora de forma inconclusiva, que melhoras no quadro clínico de crianças com TEA atendidas em musicoterapia podem ser acompanhadas de melhoras na qualidade de vida dos pais destas crianças. No trabalho de FREIRE foi dada prioridade ao uso de estruturas musicais denominadas temas clínicos nas improvisações musicais coativas de modo a favorecer a comunicação entre paciente e terapeuta. A partir de motivos musicais melódicos e/ou rítmicos espontaneamente realizados pelo paciente, o musicoterapeuta busca desenvolver frases musicais elaboradas e as utiliza para favorecer a interação durante a improvisação musical, reconhecendo a presença do paciente e validando a sua participação através da música.

ELEFANT (2001, 2005), em uma pesquisa envolvendo escolha de canções com meninas com Síndrome de $\operatorname{Rett}^{8}$, verifica que ao longo de um processo quasiexperimental,

8 A Síndrome de Rett (SR) compunha, no DSM-IV-TR, o grupo de Transtornos Invasivos do Desenvolvimento, ao lado do Transtorno Autístico e de outros transtornos que apresentam características autísticas relevantes. Porém, no DSM-5, esta síndrome não foi contemplada como parte do Transtorno do Espectro do Autismo. Ressalta-se, no entanto, a presença de comportamentos autísticos em meninas com SR principalmente na primeira década de vida (APA, 1995, 2014). 
individualizado, com linhas de base múltiplas as pacientes conseguem efetivamente escolher canções, responder apropriadamente às canções, demonstrar antecipação de elementos e eventos nas canções e responder a eles com tempos de resposta regulares, demonstrando habilidades de aprendizagem consistentes. ELEFANT (2005) descreve vários parâmetros musicais importantes destas canções para o estabelecimento do processo comunicacional, com destaque para familiaridade das canções, andamento rápido porém com variações de andamento ao longo das canções, e presença de elementos surpresa ou inusitados. Isto é, na composição e execução das canções, o musicoterapeuta deve conjugar a previsibilidade e a surpresa, a manutenção e a variabilidade.

KERN e colaboradores (KERN; ALDRIDGE, 2006; KERN; WOLERY; ALDRIDGE, 2007) utilizaram canções com crianças de até quatro anos de idade com TEA para aprendizagem de comportamentos. Estas canções são individualizadas e, por meio de um processo de linha de base múltiplas, verificaram melhora na interação social com outras crianças em ambientes lúdicos como no playground e aprendizagem de comportamentos de rotina em sala de aula cumprimentando os colegas verbalmente e por meio de gestos e envolvimento nas atividades lúdicas escolares. Ressalta-se a importância do aprendizado das canções e da sua rotina de uso pelos professores das escolas participantes para a efetiva melhora de interação e outros comportamentos das crianças com TEA.

LIM e DRAPER (2011) desenvolveram um estudo experimental com 22 crianças com TEA entre três e cinco anos de idade com foco na utilização da música em conjunto com Applied Behavior Analysis - Verbal Behavior Approach (Análise Aplicada de Comportamento Comportamento Verbal) para o treinamento de fala. Em especial em relação aos comportamentos de eco (repetição da fala pela criança após a produção verbal do adulto), a música se mostrou um efetivo meio de treinamento.

WIMPORY, CHADWICK e NASH (1995) realizaram intervenções musicoterapêuticas com uma criança com TEA de três anos e sua mãe, e verificaram melhora substancial na interação e comunicação entre elas, sendo tais melhoras também generalizadas para outras situações fora do setting musicoterapêutico. A díade mãe-criança foi acompanhada em follow up e verificou-se manutenção destes comportamentos por dois anos. 
WHIPPLE (2012) realizou uma meta-análise de artigos sobre intervenções clínicas musicoterapêuticas individuais ou grupais com crianças com TEA de até cinco anos de idade, encontrando oito estudos que respondiam aos seus critérios de inclusão. Verificou que a maioria destes estudos focava no aumento de habilidades comunicação, relação interpessoal, autocuidados e lazer, sendo a diminuição de comportamentos considerados aberrantes ou inadequados consequência do desenvolvimento geral de habilidades. $O$ tratamento musicoterapêutico, nestes estudos, se constrói e se estabelece principalmente a partir de objetivos positivos (desenvolvimento de habilidades) mais do que dos negativos (remissão de sintomas ou diminuição de comportamentos inadequados). O estudo também utilizou os critérios estabelecidos por Reichow, Volkmar e Cicchetti, citados por WHIPPLE (2012), encontrando nível de forte evidência para quatro dos oito estudos e, de evidências adequadas, para os demais ${ }^{9}$. Utilizando o parâmetro estatístico $d$ de Cohen, a autora também verifica um tamanho de efeito de médio a grande para todos os estudos, além de outras correlações que suportam a utilização da musicoterapia como um tratamento efetivo para crianças com TEA, em especial no desenvolvimento da comunicação, relação interpessoal, autocuidados e lazer.

Todavia, deve ser levado em consideração que em vários estudos e relatos de processos clínicos musicoterapêuticos com pessoas com TEA, tanto os avaliados por WHIPPLE (2012) em sua meta-análise como em vários dos demais estudos já citados, são utilizados para avaliação da eficácia do atendimento parâmetros não musicais, externos ao atendimento clínico musicoterapêutico tais como escalas de relato de comportamentos como, por exemplo, KERN e ALDRIDGE (2006) e GATTINO et al. (2011). Nos últimos anos, vários musicoterapeutas têm tentado encontrar modos de avaliação e verificação de eficácia do processo clínico musicoterapêutico utilizando parâmetros musicais e, portanto, internos a este processo clínico.

9 WHIPPLE (2012) relata que o critério estabelecido por Reichow, Volkmar e Cicchetti para qualificar práticas baseadas em evidência possui três categorias: fraco, adequado e forte. Este critério foi utilizado em sua meta-análise por incorporar também estudos de caso único experimentais, embora estes sejam contabilizados com peso inferior a estudos com número de sujeitos mais robusto. WHIPPLE (2012) informa, ainda, que segundo Reichow, Volkmar e Cicchetti, um tratamento pode ser classificado como possuindo "prática baseada em evidências estabelecida" com um mínimo de cinco estudos de caso único experimentais de forte integridade científica ou dez de integridade científica adequada. Uma classificação de "prática baseada em evidência promissora" necessita de, ao menos, três estudos de caso único experimentais de adequada integridade científica. Para a qualificação do nível de integridade científica para esta população clínica (pessoas com TEA), WHIPPLE (2012) utiliza os critérios descritos no National Standards Repport do National Autism Center, publicado em 2009. 
Em 2007, os musicoterapeutas Thomas Wosch e Tony Wigram organizaram e publicaram um livro sobre microanálise em pesquisa em Musicoterapia. Estes autores explicam que a microanálise consiste em uma análise detalhada de pequenos porém relevantes trechos de sessões de um processo clínico ou mesmo de uma única sessão deste processo ou intervenção e, em musicoterapia, o foco desta análise está dirigido para mínimas mudanças nas relações ou interações entre as pessoas ou para mínimas mudanças na produção musical. Apesar do uso de tal metodologia não ser recente na literatura musicoterapêutica, foi esparsamente utilizada nas últimas décadas do século XX, tendo maior utilização e sistematização na primeira década do século XXI (WOSCH; WIGRAM, 2007).

Para WOSCH e WIGRAM (2007, p.22, tradução nossa),
A microanálise é um método detalhado de investigação de microprocessos. Microprocessos são processos ou mudanças/progressões dentro de uma sessão de musicoterapia. O tamanho de amostra temporal pode ser um minuto (momento) ou cinco minutos (evento terapêutico) de uma sessão, uma improvisação clínica (episódio), ou uma sessão completa. Para analisar o transcorrer do processo, podem ser realizadas diversas microanálises para verificar diversos eventos.

Embora em psicoterapia tenham sido descritos seis níveis de microanálise em função do espaço temporal considerado, WOSCH e WIGRAM (2007) consideram apenas quatro níveis como relevantes para a pesquisa em musicoterapia: 1) Sessão; 2) Episódio (uma improvisação, uma verbalização sobre a experiência musical, uma atividade de apreciação musical etc.); 3) Evento terapêutico (p.e., uma frase musical ou verbal); e, 4) Mudança experienciada momento a momento (interação momento a momento, emoção expressa momento a momento etc.). Este quarto nível, mudança momento a momento, consiste no processo cognitivo que reside no menor nível individual de experiência, como a menor subdivisão possível, necessitando definição a cada trabalho de pesquisa sobre qual seria a unidade mínima de significado (menor signo) capaz de trazer informações relevantes sobre o foco de estudo. Os autores consideram, ainda, que a microanálise pode ser utilizada tanto em pesquisas quantitativas como qualitativas, envolvendo o produto musical gerado nas sessões de musicoterapia (a partir da produção realizada pelo terapeuta e/ou pelo paciente), as verbalizações que ocorrem no setting terapêutico ou, ainda, os comportamentos não musicais relevantes para o quadro clínico em questão, por exemplo, no TEA, podem ser considerados o contato visual, o comportamento agressivo, entre outros. 
PLAHL (2007) descreve um caso clínico musicoterapêutico com um menino de cinco anos de idade com TEA no qual foi utilizada a microanálise de duas sessões para verificar o desenvolvimento de habilidades pré-verbais de comunicação. Considera que o desenvolvimento de habilidades pré-verbais de comunicação, como parte do desenvolvimento global, ocorre por meio da interação de processos biológicos, psicológicos, socioculturais e alterações no espaço físico. Terapeuta e paciente são considerados interdependentes e mutuamente determinados neste processo. $\mathrm{O}$ desenvolvimento de processos e habilidades comunicativas é suportado tanto por parâmetros de estruturação musicais como por interações coordenadas que são caracterizadas por coerência, sincronicidade e reciprocidade. Neste contexto, coerência implica em situações recorrentes que o terapeuta cria nas quais a regularidade de elementos e rituais musicais são importantes elementos de estruturação, facilitando o desenvolvimento de processos perceptivos e cognitivos da criança. As expectativas geradas (e atendidas) favorecem a compreensão da situação ambiental e das ações do outro. Por outro lado, a sincronicidade (nesta abordagem) compreende a ressonância do terapeuta às ações e afetos da criança por meio de feedbacks sonoros, musicais e/ou comportamentais. É favorecida, então, a expressão emocional da criança bem como é fortalecida a habilidade de autorregulação e noção de auto eficácia. Por último, reciprocidade significa que o musicoterapeuta cria um jogo dialógico por meio de troca de turnos que permite a regulação do comportamento de ambos, individualmente e como díade.

PLAHL (2007) desenvolve seu trabalho de atendimento clínico para pesquisa com uma fase de cinco sessões de aproximadamente 30 minutos de duração cada, seguida por um intervalo de aproximadamente três ou quatro meses sem atendimento, voltando a uma outra fase de cinco sessões de musicoterapia. Comparando os resultados de microanálises das sessões (cinco minutos iniciais e cinco minutos finais de cada sessão), observou melhora significativa na atenção compartilhada tanto dentro de cada sessão, como no processo terapêutico. Além disso, foram observados uma maior quantidade de vocalizações com conteúdos emocionais e o aumento de gesticulação convencional (em comparação com estereotipias). Ainda, a porcentagem de atos intencionais de comunicação (neste estudo definidos como quaisquer ações no instrumento musical acompanhados pelo olhar em 
direção ao terapeuta), sinalizando uma referência comunicacional após uma colaboração comunicacional, também aumentou significativamente ao longo das duas fases de atendimento.

Contudo, deve-se considerar que tanto o estudo de PLAHL (2007) como outros apresentados no livro de Wosch e Wigram (WIGRAM, 2007; ABRAMS, 2007; e, WOSCH, 2007, dentre outros) utilizam sempre a seleção de alguns trechos dos atendimentos para a microanálise, o que, por um lado, diminui consideravelmente a quantidade de trabalho e tempo necessário para o estudo mas, por outro, pode introduzir um viés na pesquisa pelo fato dos trechos analisados serem selecionados com parâmetros indicados pelo pesquisador. WIGRAM (2007) afirma que uma solução ideal para este problema seria a utilização de trechos randomicamente selecionados para a análise, diminuindo a quantidade de trabalho e garantindo maior confiabilidade científica; porém, até este momento não foram encontrados na literatura musicoterapêutica nenhum estudo que tenha realizado a microanálise de trechos randomicamente selecionados, tampouco do processo clínico inteiro.

Como foi relatado até o momento, há nas literaturas específicas da musicoterapia e das neurociências muitos estudos que sugerem que a prática clínica musicoterapêutica pode promover melhora nas condições de saúde de pessoas com Transtorno do Espectro do Autismo. Um questionamento que pode ser levantado, no entanto, consiste em que muitos critérios de avaliação destas melhoras (tanto na clínica musicoterapêutica com em outras áreas) possuem um forte caráter subjetivo, dependendo muito das impressões e considerações do observador, como pode ser verificado no trabalho de ALVIN (1978), BENENZON (1985), BRANDALISE (2001), CRAVEIRO DE SÁ (2003), FLEURY e PINHEIRO (2013), entre outros. Há atualmente um grande movimento na área de musicoterapia e de outras modalidades terapêuticas, tanto no Brasil como em outros países, de uma busca por práticas baseadas em evidências e por meios de avaliação que sejam mais observador-independentes. 


\section{3 - Uma abordagem clínica musicoterapêutica informada pelas neurociências para o atendimento a pessoas com TEA}

Para SAMPAIO (2002), primeiro autor deste artigo, no trabalho clínico musicoterapêutico com crianças com TEA ou com outros distúrbios do desenvolvimento com grande comprometimento na comunicação, em muitas ocasiões, o musicoterapeuta deve inicialmente convidar o paciente a participar na experiência musical, construindo, descontruindo e reconstruindo com ele um novo território musical. O terapeuta, nestas situações, deve tomar uma atitude mais diretiva no sentido de chamar a atenção do paciente para o estímulo sonoro e sua possibilidade de uso para estabelecer novos meios de comunicação. Entende-se nesta perspectiva que a comunicação, como definido por MATURANA (1999), consiste em coordenação consensual de comportamentos.

Quando o paciente responde a este convite para participar coativamente na experiência musical, o musicoterapeuta adapta seu fazer musical para incluir o que o paciente está produzindo, respondendo, imitando, espelhando, enfatizando, desenvolvendo motivos musicais ou utilizando qualquer outra forma possível de reconhecimento, validação e interação musical.

A partir do momento em que o paciente e o musicoterapeuta iniciam um processo de comunicação musical, ou seja, um processo de coordenações consensuais de ações musicais, não somente a relação entre eles se desenvolve como também as próprias habilidades musicais e não-musicais do paciente. Este desenvolvimento é recursivo ao longo de todo o processo clínico musicoterapêutico com contribuições ou induções do terapeuta e do paciente e, deste modo, a complexidade da produção musical da díade musicoterapeutapaciente vai sendo gradativamente aumentada (SAMPAIO, 2002). (Figura 1) 


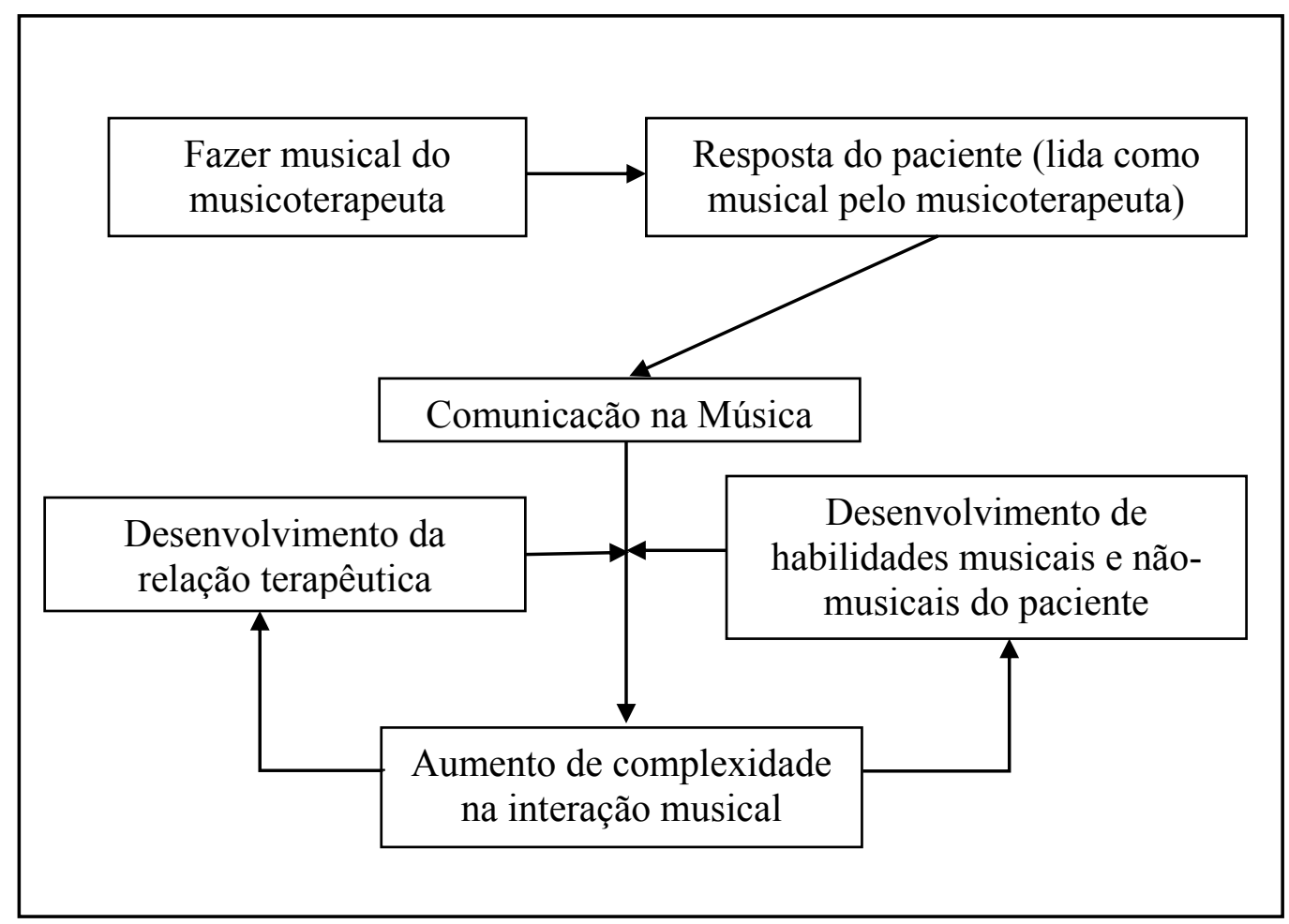

Figura 1: Representação esquemática do modelo criado por SAMPAIO (2002) para descrever o fluxo do processo clínico musicoterapêutico com pacientes com distúrbios do desenvolvimento com comprometimento da comunicação.

O musicoterapeuta, por meio de suas intervenções musicais e não musicais, como as verbais e/ou as gestuais, irá modular a atenção, a cognição, a emoção, a comunicação e o comportamento do paciente para alcançar os objetivos clínicos relevantes para cada caso (PAVLICEVIC, 1990; HILLECKE; NICKEL; BOLAY, 2005). No atendimento a pessoas com TEA, um dos ojetivos é ultrapassar o ritualismo típico presente na manipulação de objetos por pessoas com TEA para alcançar e desenvolver a atenção compartilhada, favorcendo, deste modo, um desenvolvimento mais efetivo de processos de comunicação e de interação social.

Segundo McFERRAN e SHOEMARK (2013), em uma abordagem musicoterapêutica ativa com pessoas significativamente comprometidas em termos cognitivos, resultados positivos do processo terapêutico não dependem somente do estímulo musical utilizado de modo correto, mas também e, em alguns casos, principalmente, da relação terapêutica construída. O terapeuta deve possuir a habilidade de estar-com-o-outro de modo atento, responsivo e 
criativo. Ele deve escutar seu paciente e ser responsável pela estrutura da sessão e da música, facilitando e validando uma iniciação musical espontânea do paciente. A experiência clínica tem demonstrado que o mesmo é válido para a atuação musicoterapêutica com pessoas com TEA.

Pode-se ilustrar este esquema com a descrição de uma situação clínica comum no processo musicoterapêutico como pessoas com autismo: um jogo musical no qual o musicoterapeuta e o paciente devem cantar uma pequena canção e fazer os movimentos solicitados como bater palmas sozinho, bater palmas com o outro, bater na perna e em outras partes do corpo. Em uma díade, terapeuta e paciente devem se posicionar de frente um para o outro e os movimentos são realizados nos tempos recorrentes da pulsação rítmica. O prazer proporcionado pela ação musical e o movimento são essenciais para despertar o interesse do paciente para a participação e o engajamento na atividade.

O musicoterapeuta é responsável inicialmente por cantar e ensinar os movimentos ao paciente, modulando o fluxo temporal da música para ajustá-la às condições e habilidades do paciente naquele momento, por exemplo, alterando o andamento para se ajustar à condição de coordenação motora do paciente ou suspendendo o fluxo da música para aguardar o paciente realizar a ação motora. Aos poucos, com a repetição do jogo, o paciente irá sincronizar os movimentos com a canção e interagir fisicamente e musicalmente com o terapeuta. Se o paciente for verbal, pode-se solicitar que ele cante junto com o terapeuta, que ele cante sozinho a canção ou que terapeuta e paciente alternem trechos ou frases da canção.

Uma vez aprendida a canção e a sequência de movimentos, mesmo que ainda com algumas falhas na realização, o musicoterapeuta pode iniciar variações para explorar uma nova situação e desenvolver interação social, além da atenção, a prontidão para a resposta, a linguagem, a coordenação motora e vários outros elementos. Ele pode, por exemplo, fazer variações de andamento (andamentos mais rápidos ou mais lentos e, até mesmo, acelerandos e diminuendos ao longo da atividade), de tonalidade (a cada repetição cantar numa tonalidade diferente) ou mesmo variar os movimentos a serem realizados e cantados. 
Caberá ao musicoterapeuta, em função dos objetivos clínicos traçados e às condições do paciente decidir quais variações seriam mais pertinentes naquela sessão, indo desde aceitar e lidar com a mudança e o contato físico até cantar as frases completas da canção com boa compreensibilidade da produção vocal, coordenar movimentos áudio-motores, estimular a atenção e a memória, favorecer o engajamento social, treinar a antecipação e a prontidão de respostas, entre vários outros.

É importante ressaltar que a atividade descrita acima consiste tão somente em um exemplo de como o desenvolvimento da habilidade de fazer música com o outro pode ser abordado no fazer musicoterapêutico de modo a promover as mudanças necessárias para a melhora clínica do paciente. A abordagem proposta por SAMPAIO (2002) não é uma proposta metodológica fechada, de passos estritramente determinados a serem seguidos. Pelo contrário, trata-se de uma abordagem aberta na qual a cada instante o musicoterapeuta deverá reconhecer o contexto e avaliar quais intervenções são adequadas e necessárias para alcançar o objetivo terapêutico traçado.

Este é um modo bottom-up ${ }^{10}$ de conceber o tratamento no sentido que a experiência musical propicia um processamento cerebral da experiência vivida mais integrado que através de outras modalidades como a da fala e, deste modo, facilita a criação de novas conexões neurais ou o reforço de conexões fracas ou instáveis. Espera-se, então, que tal fato resulte em condutas mais funcionais, apropriadas e efetivas. $O$ prazer que o engajamento na atividade musical pode proporcionar (KOELSCH, 2014) é fundamental para a manutenção do foco atencional para a atividade e propicia a criação de um território musical no qual o paciente e o terapeuta irão se encontrar e interagir (SAMPAIO, 2007).

Considerando a explicação conexionista do autismo apresentada anteriormente, a repetição de uma experiência é importante para a construção de memória mas não se deve repeti-la sempre do mesmo modo, senão um novo ritual autístico pode ser introduzido ou algum

$10 \mathrm{O}$ termo bottom-up se refere ao conceito em neurociências segundo o qual o processamento mais básico da informação em nível cortical, e, portanto, mais dependente do estímulo externo, tem primazia sobre aspectos como expectativas, conhecimento armazenado, contexto e assim por diante. Estudos como os de AMSO et al. (2014) e COOK et al. (2012) sugerem que pessoas com autismo possuem maior incidência de comportamentos dirigidos por estímulos, isto é, processados de modo bottom-up, que pessoas com desenvolvimento típico. Para tais pesquisadores, tal fato estaria relacionado aos prejuízos na interação social apresentados pelas pessoas com autismo. 
existente pode ser reforçado. Portanto, é imperativo conjugar repetição e variação, bem como familiaridade e surpresa ao longo de todo o tratamento e, especificamente, em cada interatividade musical entre paciente e musicoterapeuta.

\section{4 - Considerações Finais}

Estudos recentes em neurociências têm trazidos novas luzes sobre a estrutura e funcionamento do sistema nervoso de pessoas com Transtorno do Espectro do Autismo, incluindo o modo como esta população processa a música. A utilização destes conhecimentos pela área da musicoterapia fornece novas explicações a respeito do modo pelo qual a música pode ser utilizada no contexto de uma relação terapêutica para promover melhora da saúde bem como para subsidiar novas abordagens clínicas de tratamento, diagnóstico e avaliação do processo terapêutico de pessoas com TEA.

Pudemos identificar que várias pesquisas clínicas têm demonstrado a eficácia do tratamento musicoterapêutico para pessoas com TEA principalmente em relação à interação social e à comunicação. Deve-se observar, no entanto, que boa parte das pesquisas quantitativas nesta área utiliza preferencialmente modelos de avaliação utilizando parâmetros não musicais e que, então, modos sistematizados de observação e análise do comportamento musical devem ser desenvolvidos.

De acordo a proposta de SAMPAIO (2002), ao longo do processo terapêutico, pode-se considerar que não apenas o paciente apresentaria melhoras em áreas do desenvolvimento não-musicais como, também, desenvolveria habilidades musicais, embora este não seja o objetivo primário da musicoterapia. Deste modo, surge a questão referente a possibilidade de avaliar uma melhora terapêutica também a partir de algum parâmetro musical. Nos trabalhos mencionados neste artigo, muitos pesquisadores em musicoterapia têm buscado solucionar tal problema mas ainda há uma carência na literatura a respeito de como avaliar a eficácia do tratamento musicoterapêutico por meio de uma análise da produção musical coativa entre paciente e terapeuta. Portanto, mais estudos são necessários a este respeito 
tanto em relação ao desenvolvimento das habilidades musicais ao longo do processo musicoterapêutico como da relação entre o desenvolvimento de tais habilidades com as melhoras clínicas em pessoas com TEA.

Foi apresentada uma proposta clínica baseada na compreensão do desenvolvimento musical em musicoterapia de SAMPAIO (2002) com uma configuração propostidamente aberta, isto é, sem seguir passos metodológicos aprioristicamente definidos. Caberá ao musicoterapeuta, a cada instante, articular os objetivos terapêuticos e seus conhecimentos prévios sobre o paciente e sobre o percurso clínico desenvolvido até aquele instante ao contexto daquele momento para avaliar quais intervenções são pertinentes e necessárias para alcançar o objetivo terapêutico traçado. O fazer musical do musicoterapeuta será direcionado tanto por sua formação musical prévia como pela sua experiência musical e, de modo prioritário, pelas necessidades e condições clínicas do paciente. Nos atendimentos musicoterapêuticos a pessoas com autismo, busca-se um "estar com o outro" na experiência musical e, em seguida, modula-se esta experiência musical para favorecer o desenvolvimento de processos mais saudáveis de comunicação verbal e não-verbal e de interação social que pode ser observado no aumento da complexidade deste fazer musical compartilhado entre musicoterapeuta e paciente.

\section{Referências}

1. ABRAMS, B. (2007). "The Use of Improvisational Assessment Profiles (IAPs) and ReGrid in Microanalysis of Clinical Music Improvisation”. In: WOSCH, T.; WIGRAM, T. (Eds.) Microanalysis in Music Therapy. London: Jessica Kingsley.

2. ADAMEK, M.; THAUT, M.; FURMAN, A.G. (2008). "Individuals with Autism and Autism Spectrum Disorders". In: DAVIS, W.; GFELLER, K.; THAUT, M. An Introduction to Music Therapy: Theory and Practice. 3a ed. Silver Spring, EUA: American Music Therapy Association.

3. ALLEN, R.; DAVIS, R.: HILL, E. (2013). "The Effects of Autism and Alexithymia on Physiological and Verbal Responsiveness to Music". JAutismDevDisord. v.43, p.432444.

4. ALVIN, J. (1978). Music Therapy for the Autistic Child. London: Oxford University Press.

5. AMARAL, D. SCHUMANN, C.; NORDAHL, C. (2008). "Neuroanatomy of Autism". 
Trends in Neurosciences. n.3, v.31, p.137-145.

6. AMERICAN PSYCHIATRIC ASSOCIATON (APA) (1995). Manual Diagnóstico e Estatístico de Transtornos Mentais DSM-IV. CD-ROM. Porto Alegre: Artes Médicas.

7. (2014). Manual Diagnóstico e Estatístico de Transtornos Mentais DSM-5. Porto Alegre: Artmed.

8. AMSO, D.; HAAS, S.; TENEBAUM, E.; MARKANT, J.; SHEINKOPF, S. (2014). "Bottom-up Attention Orienting in Young Children with Autism". JAutismDevDisord. n.3, v.44, p.664-673.

9. ANDRADE, B.; PIMENTA, A. (sine data). Musicoterapia - um caminho. Belo Horizonte: Imagem.

10. ARAUJO, C. (2000). O Processo de Individuação no Autismo. São Paulo: Memnon.

11. ASSUMPÇÃO JR., F.; KUCZYNSKI, E., GABRIEL, M.; ROCCA, C. (1999). "Escala de Avaliação de Traços Autísticos: Validade e Confiabilidade de uma escala para a detecção de condutas autísticas". ArqNeuropsiquiatr. n.1, v.57, p.23-29.

12. BALL, C. M. (2004). Music Therapy for Children with Autistic Spectrum Disorder. London: Bazian Ltd.

13. BARCELLOS, L. (2004). Musicoterapia: Alguns Escritos. Rio de Janeiro: Enelivros.

14. BARTELS, A.; ZEKI, S. (2004). "The neural correlates of maternal and romantic love". NeuroImage. v.21, p.1155-1166.

15. BENENZON, R. (1985). Manual de Musicoterapia. Rio de Janeiro: Enelivros.

16.

Rio de Janeiro: Enelivros. (1987). O Autismo, a Família, a Instituição e a Musicoterapia.

17. BERGER, D. (2002). Music Therapy, Sensory Integration and the Autistic Child. London: Jessica Kingsley.

18. BHAT, A.; LANDA, R.; GALLOWAY, J. (2011). "Current Perspectives on Motor Functioning in Infants, Children and Adults with Autism Spectrum Disorders”. Physical Therapy. n.7, v.91, p.1116-1129.

19. BHATARA, A.; QUINTIN, E.; HEATON, P; FOMBONNE, E; LEVITIN, D.J. (2009). "The effect of music on social attribution in adolescents with autism spectrum disorders". Child Neuropsychology. v.15, p.375-396.

20. BOSA, C. (2001). "As relações entre Autismo, Comportamento Social e Função Executiva”. Psicologia: Reflexão e Crítica. n.2, v.14, p.281-287.

21. (2009). “Compreendendo a evolução da comunicação no bebê: implicações para a identificação precoce no autismo”. In: HAASE, V.; FERREIRA, F.; 
PENNA, F. Aspectos Biopsicossociais da Saúde na Infância e Adolescência. Belo Horizonte: Coopmed.

22. BOSA, C.; CALLIAS, M. (2000). "Autismo: breve revisão de diferentes abordagens". Psicologia: Reflexão e Crítica. n.1, v.13, p.167-177.

23. BOXILL, E. (1985). Music Therapy for the Develomentally Disabled. Austin, EUA: Pro-Ed.

24. BRANDALISE, A. (1998). “Approach Brandalise de Musicoterapia - Carta de Canções”. Revista Brasileira de Musicoterapia. n.4, p.41-55.

25. (2001). Musicoterapia Músico-Centrada. São Paulo:

Apontamentos.

26. BRATTICO, E.; ALLURI, V.; BOGERT, B. JACIBSEN, T.; VARTIAINEN, N.; NIEMINEN, S. TERVANIEMI, M. (2011). "A functional MRI study of happy and sad emotions in Music with and without lyrics". Frontiers in Psychology. v.2, article 308, p.116.

27. BROWN, S. (1994). “Autism and music therapy: is change possible and why music?". British Journal of Music Therapy. n.1, v.8, p.15-20.

28. BROWNELL, M. (2002). "Musically adapted social stories to modify behaviors in students with autism: four case studies". Journal of Music Therapy. n.2, v.XXXIX, p.117-144.

29. BRUSCIA, K. (2000). Definindo Musicoterapia. Rio de Janeiro: Enelivros.

30. BUDAY, E. (1995). "The effects of signed and spoken words taught with music on sign and speech imitation by children with autism". Journal of Music Therapy. v.32, p.189-202.

31. CAMARGO, S.; BOSA, C. (2012). "Competência Social, Inclusão Escolar e Autismo: Um estudo de caso comparativo". Psicologia: Teoria e Pesquisa. n.3, v.28, p.315-324.

32. CAMPELO, L.; LUCENA, J.; LIMA, C.; ARAUJO, H.; VIANA, L.; VELOSO, M.; CORREIA, P.; MUNIZ, L. (2009). "Autismo: um estudo de habilidades comunicativas em crianças”. RevCEFAC. n.4, v.11, p.598-606.

33. CARIA, A. VENUTI, P. FALCO, S. (2011). "Functional and Dysfunctional Brain Circuits Underlying Emotional Processing of Music in Autism Spectrum Disorders".

Cerebral Cortex. v.21, p.2838-2849.

34. CARVALHEIRA, G.; VERGANIB, N.; BRUNONI, D. (2004). "Genetics of Autism". RevBrasPsiquiatr. n.4, v.26, p.270-272.

35. COOK, J.; BARBALAT, G.; BLAKEMORE, SJ. (2012). "Top-down modulation of the perception of other people in schizophrenia and autism". Frontiers in Human Neuroscience. v.6, article 175, p.1-10. 
36. COSENZA, R. (1998) Fundamentos de Neuroanatomia. 2. Ed. Rio de Janeiro: Guanabara Koogan.

37. CRAVEIRO DE SÁ, L. (2003). A teia do tempo e o autista: música e musicoterapia. Goiânia: UFG.

38. DICHTER, G. (2012). "Functional magnetic resonance imaging of autism spectrum disorders". DialoguesClinNeurosci. n.3, v.14, p.319-351.

39. DICHTER, G.; FELDER, J.; BODFISH, J. (2009)." Autism is characterized by dorsal anterior cingulated hyperactivation during social target detection". SCAN. n.3, v.4, p.215226.

40. EDGERTON, C. (1994). "The effect of improvisational music therapy on the communicative behaviors of autistic children". Journal of Music Therapy. v.31, p.31-62.

41. ELEFANT, C. (2001). "Speechless yet communicative: revealing the person behind the disability of Rett Syndrome through clinical research on songs in music therapy". In: ALDRIDGE, D.; Di FRANCO, G.; RUUD, E.; WIGRAM, T. (Eds.) Music Therapy in Europe. Rome: ISMEZ.

42. (2005). "The Use of Single Case Designs in Testing Hypothesis". In: ALDRIDGE, D. (Ed.) Case Study Designs in Music Therapy. London: Jessica Kingsley.

43. FERREIRA, P.; TEIXEIRA, E.; BRITTO, D. (2011). "Relato de Caso: Descrição da evolução da comunicação alternativa na pragmática do adulto portador de autismo".

RevCEFAC. n.3, v.13, p.559-567.

44. FILIPIC, S.; BIGAND, E. (2004). "The Time-course of emotion and cognition while listening to music". In: LIPSCOMB, S.; ASHLEY, R.; GJERDINGEN, R.; WEBSTER, P. (Eds.) Proceedings of the $8^{\text {th }}$ International Conference on Music Perception \& Cognition. Adelaide (Australia): Casual Productions.

45. FLEURY, E.; PINHEIRO, L. (2013). Dois Casos Musicoterapêuticos: desafios e conquistas. Goiânia: Kelps.

46. FREIRE, M. (2014). Efeitos da Musicoterapia Improvisacional no tratamento de crianças com Transtorno do Espectro do Autismo. Dissertação (Mestrado em Neurociências). Programa de Pós-Graduação em Neurociências. Universidade Federal de Minas Gerais. Belo Horizonte.

47. FRITZ, T.; JENTSCHKE, S.; GOSSELI, N.; SAMMLER, D.; PERETZ, I.; TURNER, R.; FRIEDERICI, A.D.; KOELSCH, S. (2009). "Universal recognition of three basic emotions in music". CurrBiol. v.19, p.1-4.

48. GARCIA, H.; USTARROZ, J.; LOPEZ-GOÑI, J. (2012). "Valoración de la cognición social en esquizofrenia a través del test de la mirada. Implicaciones para la rehabilitación". Avances en Psicologia Latinoamericana. n.1, v.30, p.40-52. 
49. GATTINO, G.; RIESGO, R.; LONGO, D.; LEITE, J.; FACCINI, L. (2011). "Effects of relational music therapy on communication of children with autism: a randomized controlled study". Nordic Journal of Music Therapy. n.2, v.20, p.142-154.

50. GIRODO, C.; NEVES, M.; CORREA, H. (2008). “Aspectos Neurobiológicos e Neuropsicológicos do Autismo”. In: FUENTES, D.; MALLOY-DINIZ, L.; CAMARGO, C.; COSENZA, R. (Eds) Neuropsicologia Teoria e Prática. Porto Alegre: Artmed.

51. GFELLER, K. (2008). "Music: a Human Phenomenon and Therapeutic Tool”. In: DAVIS, W.; GFELLER, K.; THAUT, M. An Introduction to Music Therapy: Theory and Practice. 3. Ed. Silver Spring: American Music Therapy Association.

52. GOLD, C.; WIGRAM, T.; ELEFANT, C. (2006). "Music therapy for autistic spectrum disorder”. CochraneDatabaseSystRev. v.2, article CD004381.

53. GOSSELIN, N.; PERETZ, I.; HASBOUN, D.; BAULAC, M.; SAMSON, S. (2011). "Impaired recognition of musical emotions and facial expressions following anteromedial temporal lobe excision”. Cortex. v.47, p.1116-1125.

54. GOSSELIN, N.; PERETZ, I.; JOHNSEN, E.; ADOLPHS, R. (2007). “Amygdala damage impairs emotion recognition from music". Neuropsychologia. v.45, p.236-244.

55. GUPTA, A.; STATE, M.W. (2006). “Autismo: Genética”. RevBrasPsiquiatr. v.28 (Supl I), p.S29-38.

56. HILLECKE, T.; NICKEL, A.; BOLAY, H. (2005). "Scientific Perspectives on Music Therapy". AnnNYAcadSci. v.1060, p.271-282.

57. HURON, D. (2006). Sweet anticipation: music and the psychology of expectation. Cambridge, EUA: MIT Press.

58. ILARI, B. (2006). "Desenvolvimento cognitivo-musical no primeiro ano de vida". In. ILARI, B. Em busca da mente musical. Curitiba: UFPR.

59. KENET, T.; OREKHOVA, E.; BHARADWAJ, H.; SHETTY, N.; ISRAELI, E.; LEE, A.; AGAM, Y.; ELAM, M. JOSEPH, M. HAMALAINEN, M.; MANOACH, D. (2012). "Disconnectivity of the cortical ocular motor control network in autism spectrum disorders". NeuroImage, v.61, p.1226-1234.

60. KENNEY, S. (2008). "Birth to six: music behaviors and how to nurture them". General Music Today. n.1, v.22, p.32-34.

61. KERN, P.; ALDRIDGE, D. (2006). "Using embedded music therapy interventions to support outdoor play of young children with autism in an inclusive community-based child care program". Journal of Music Therapy. n.4, v.XLIII, p.270-294.

62. KERN, P.; WOLERY, M.; ALDRIDGE, D. "Use of songs to promote independence in morning greeting routines for young children with autism". JAutismDevDisor. v.37, p.1264-1271. 
63. KIM, J.; WIGRAM, T.; GOLD, C. (2009). "Emotional, motivational and interpersonal responsiveness of children with autism in improvisational music therapy". Autism. n.4, v.13, p.389-409.

64. KLIN, A. (2006). “Autismo e Síndrome de Asperger: uma visão geral”.

RevBrasPsiquiatr. n.28 (Supl I), p.S3-S11.

65. KOELSCH, S. (2009). "A Neuroscientific Perspective on Music Therapy”. AnnNYAcadSci. v.1169, p.374-384.

66. (2011). "Toward a neural basis of music perception - a review and updated model”. Frontiers in Psychology. v.2, article 110, p.1-20.

67. (2014). "Brain correlates of music-evoked emotions". Nature

Reviews Neuroscience. v.15, p.170-180.

68. KOELSCH, S.; FRITZ, T.; CRAMON, D.; MULLER, K.; FRIEDERICI, A. (2006). "Investigating emotion with music: an fMRI study". HumBrainMapp. v.27, p.239-250.

69. LAI, G.: PANTAZATOS, S.; SCHNEIDER, H.; HIRSCH, J. (2012). "Neural systems for speech and song in autism". Brain. v.135, p.961-975.

70. LENT, R. (2010). Cem bilhões de neurônios? 2. Ed. São Paulo: Atheneu.

71. LIM, H.; DRAPER, E. (2011). "The effects of music therapy incorporated with Applied Behavior Analysis Verbal Behavior approach for children with autism spectrum disorders". Journal of Music Therapy. n.4, v.48, p.532-550.

72. MALLOCH, S.; TREVARTHEN, C. (2009). "Musicality: Communicating the vitality and interests of life". In: MALLOCH, S.; TREVARTHEN, C. (Eds.). Communicative musicality: Exploring the basis of human companionship. Oxford: Oxford University Press.

73. MARANTO, C. (ed.) (1993). Music Therapy: International Perspectives.

Pipersville: Jeffrey Books.

74. MATSON, M.; MATSON, J.; BEIGHLEY, J. (2011). "Comorbidity of physical and motor problems in children with autism”. Research in Developmental Disabilities. v.32, p.2304-2308.

75. MATURANA, H. (1999). A Ontologia da Realidade. Belo Horizonte: UFMG.

76. MECCA, T.; BRAVO, R.; VELLOSO, R.; SCHWARTZMAN, J.; BRUNONI, D.; TEIXEIRA, M. (2011). "Rastreamento de sinais e sintomas de Transtorno do Espectro do Autismo em irmãos”. RevPsiquiatrRioGdSul. n.2, v.33, p.116-120.

77. McFERRAN, K.; SHOEMARK, H. (2013). "How musical engagement promotes wellbeing in education contexts: The case of a young man with profound and multiple disabilities". IntJQualitativeStudHealthWell-Being. v.8, article 20570, p.1-14. 
78. MERCADANTE, M.; POLIMENO, A. (2009). "Neuroquímica Cerebral”. In: MARCADANTE, M.; ROSÁRIO, M. Autismo e Cérebro Social. São Paulo: Farma.

79. MITTERSCHIFFTHALER, M.; FU, C.; DALTON, J.; ANDREW, C.; WILLIAMS, S. (2007). "A functional MRI study of happy and sad affective states evoked by classical music". HumBrainMapp. v.28, p.1150-1162.

80. NEUHAUS, E.; BEAUCHAINE, T.; BERNIER, R. (2010). "Neurobiological correlates of social functioning in autism". Clinical Psychology Review. v.30, p.733-748.

81. NORDOFF, P.; ROBBINS, C. (2007). Creative Music Therapy. 2. Ed. Revised. New Hampshire: Barcelona.

82. OLDFIELD, A. (2001). "Music therapy with young children with autism and their parents: developing communications through playful musical interactions specific to each child”. In: ALDRIDGE, D., DIFRANCO, G. RUUD, E.; WIGRAM, T. (Eds.) Music Therapy in Europe. Roma: Ismez.

83. OMAR, R.; HENLEY, S.; BARTLETT, J.; HAILSTONE, J.; GORDON, E.; SAUTER, D.; FROST, C.; SCOTT, S.; WARREN, J. (2011). "The structural neuroanatomy of music emotion recognition: Evidence from frontotemporal lobar degeneration”. NeuroImage. v.56, p.1814-1821.

84. ORSATI, F.; SCHWARTZMAN, J.; BRUNONI, D.; MECCA, T.; MACEDO, E. (2008). "Novas possibilidades na avaliação neuropsicológica dos transtornos invasivos do desenvolvimento: Análise dos movimentos oculares”. AvalPsicol. n.3, v.7, p.281-290.

85. PAVLICEVIC, M. (1990). "Dynamic interplay in clinical improvisation". Journal of British Music Therapy. v.4, p.5-9.

86. PASCUAL-LEONE, A. (2009). "The brain that makes music and is changed by it". In: PERETZ, I.; ZATORRE, R. The cognitive neuroscience of music. Reprint. New York: Oxford.

87. PATEL, A. (2008a). "Music as a transformative technology of the mind". In: John Templeton Foundation. Music: Its Evolution, Cognitive Basis, and Spiritual Dimensions. (Symposium). Cambridge University, September. Disponível em $<$ http://www.nsi.edu/ ani/Patel_2008_Templeton_Essay.pdf $>$. Acesso em 07 out 2014.

88. (2008b). Music, language and the brain. New York: Oxford University Press.

89. PEREIRA, A.; RIESGO, R.; WAGNER, M. (2008). “Autismo infantil: tradução e validação da Childhood Autism Rating Scale para uso no Brasil”. JPediatr. Rio de Janeiro, n.6, v.84, p487-494.

90. PLAHL, C. (2007). "Microanalysis of Preverbal Communication in Music Therapy". In: WOSCH, T.; WIGRAM, T. (Eds.) Microanalysis in Music Therapy. London: Jessica Kingsley. 
91. ROBARTS, J. (1996). "Music therapy for autistic children". In: TREVARTHEN, C.; AITKEN, K.; PAPOUDI, D.; ROBARTS, J. (Eds.) Children with Autism: Diagnosis and Interventions to Meet Their Needs. London: Jessica Kingsley.

92. RODRIGUES, A. (2012). Efeito do treinamento musical em capacidades cognitivas visuais: atenção e memória. Tese (Doutorado). Programa de Pós-Graduação em Neurociências. Universidade Federal de Minas Gerais. Belo Horizonte.

93. SAMPAIO, A.; SAMPAIO, R. (2005). Apontamentos em Musicoterapia, volume 1. São Paulo: Apontamentos Editora.

94. SAMPAIO, R. (2002). Novas Perspectivas de Comunicação em Musicoterapia. Dissertação (Mestrado) Programa de Pós Graduação em Comunicação e Semiótica. Pontifícia Universidade Católica de São Paulo. São Paulo.

95. (2006). Um estudo preliminar sobre a construção da comunicação musical em Musicoterapia. XII Simpósio Brasileiro de Musicoterapia. Anais... Goiânia, Sociedade Goiana de Musicoterapia.

96. (2007). Considerações sobre a Linguagem na Prática Clínica Musicoterapêutica numa Abordagem Gestáltica. VII Encontro Nacional da Associação de Pesquisa e Pós Graduação em Música. Anais... São Paulo, Instituto de Artes UNESP.

97. SAMSON, S.; EHRLE, N.; BAULAC, M. (2001). "Cerebral substrates for musical temporal processes". AnnNYAcadSci. v.930, p.166-178.

98. SCHWARTZMAN, J. (2011). "Neurobiologia dos Transtornos do Espectro do Autismo”. In: SCHWARTZMAN, J.; ARAUJO, C. Transtornos do Espectro do Autismo. São Paulo: Memnon.

99. SUMMER, L. (2009). Client Perspectives on the Music in Guided Imagery and Music. Thesis (Doctor in Philosophy - Dept. of Communication and Psychology). Aalborg University, Denmark.

100. TAMANAHA, A.; PERISSINOTO, J.; CHIARI, B. (2008). "Uma breve revisão histórica sobre a construção dos conceitos do Autismo Infantil e da Síndrome de Asperger". RevSocBrasFonoaudiol. n.3, v.13, p.296-299.

101. TREHUB, S. (2005). "Developmental and Applied Perspectives on Music". AnnNYAcadSci. v. 1060, p. 198-201.

102. THAUT, M. (2008). Rhythm, Music and the Brain. New York: Routledge.

103. TOWGOOD, K.; MEUWESE, J.; GILBERT, S.; TURNER, M.; BURGESS, P. (2009). "Advantages of the multiple case series approach to the study of cognitive deficits in autism spectrum disorder". Neuropsychologia. n.13, v.47, p.2981-2988.

104. VELLOSO, R.; VINIC, A.; DUARTE, C.; DANTINO, M.; BRUNONI, D.; SCHWARTZMAN, J. (2011). "Protocolo de Avaliação Diagnóstica Multidisciplinar da 
Equipe de Transtornos Globais do Desenvolvimento vinculado à Pós-Graduação em Distúrbios do Desenvolvimento da Universidade Presbiteriana Mackenzie". Cadernos de Pós-Graduação em Distúrbios do Desenvolvimento. n.1, v.11, p.9-22.

105. WIGRAM, T. (2007). "Event-based Analysis of Improvisations Using Improvisational Assessment Profiles". In: WOSCH, T.; WIGRAM, T. (Eds.) Microanalysis in Music Therapy. London: Jessica Kingsley.

106. WHIPPLE, J. (2012). "Music Therapy as an effective treatment for young children with autism spectrum disorders: a meta-analysis". In: KERN, P.; HUMPAL, M. (Eds.) Early childhood music therapy and autism spectrum disorders. London: Jessica Kingsley.

107. WIGRAM, T.; GOLD, C. (2006). Music Therapy in the assessment and treatment of autistic spectrum disorder: clinical application and research evidence. Child: care, health and development. n.5, v.32, p.535-542.

108. WIGRAM, T.; PEDERSEN, I.; BONDE, L. (2002). A Comprehensive Guide to Music Therapy: theory, clinical practice, research and training. London: Jessica Kingsley.

109. WIMPORY, D.; CHADWICK, P.; NASH, S. (1995). "Musical interaction therapy for children with autism: An evaluative case study with two-year follow up".

JAutismDevDisor. n.5, v.25, p.541-552.

110. WONG, P.; CIOCCA, V.; CHAN, A.; HA, L.; TAN, L.; PERETZ, I. (2012). "Effects of Culture on Musical Pitch Perception”. PlosOne. n.4, v.7, article e33424, p.1-8.

111. WORLD FEDERATION OF MUSIC THERAPY (2011). What is Music Therapy?. Disponível em $<$ http://www.wfmt.info/wfmt-new-home/about-wfmt/ $>$. Acesso em 10 set 2014.

112. WORLEY, J.; MATSON, J. (2011). "Psychiatric symptoms in children diagnosed with an Autism Spectrum Disorder: an examination of gender differences". Research in Autism Spectrum Disorders. v.5, p.1086-1091.

113. WOSCH, T. (2007). "Microanalysis of Processes of Interactions in Clinical Improvisation with IAP-Autonomy”. In: WOSCH, T.; WIGRAM, T. (Eds.) Microanalysis in Music Therapy. London: Jessica Kingsley.

114. WOSCH, T.; WIGRAM, T. (2007). "Microanalysis in Music Therapy: Introduction and Theoretical Basis". In: WOSCH, T.; WIGRAM, T. (Eds.) Microanalysis in Music Therapy. London: Jessica Kingsley. 
Notas sobre os autores

Renato Tocantins Sampaio é Professor Assistente do Departamento de Instrumentos e Canto da Escola de Música - UFMG e Pesquisador com Bolsa PQ Nível 2 do CNPq. Possui graduação em Musicoterapia e em Música (licenciatura) e cursa o Doutorado no Programa de Pós-Graduação em Neurociências da UFMG. Coordenador do Projeto de Extensão Clínica de Musicoterapia da UFMG que fornece atendimento musicoterapêutico a pessoas com Transtorno do Espectro do Autismo e outros transtornos do desenvolvimento.

Cybelle Maira Veiga Loureiro é Professora Adjunta do Departamento de Instrumentos e Canto da Escola de Música - UFMG. Possui graduação em Musicoterapia e em Música (Piano) e Doutorado em Ciências da Saúde (UFMG). Atua como professora nos Programas de Pós-Graduação em Música e em Neurociências na UFMG.

Cristiano Mauro Assis Gomes é Professor Associado do Departamento de Psicologia da FAFICH-UFMG e é Bolsista de Produtividade Nível 2 - CNPQ. Possui graduação em Psicologia e Doutorado em Educação (UFMG). Coordenador do Laboratório de Investigação da Arquitetura Cognitiva (LAICO) da UFMG. Atua como professor nos Programas de Pós-Graduação em Psicologia e em Neurociências na UFMG. 